\title{
AVALIAÇÃO DA CONDIÇÃO PERIODONTAL DE PACIENTES RENAIS EM HEMODIÁLISE
}

Cláudia Régia Dias de Souza, Silvana Amado libério, Rosane Nassar Meireles Guerra, Silvio Monteiro, Éricka Janine Dantas da Silveira, Antonio luiz Amaral Pereira*

Trabalho realizado no Departamento de Odontologia da Universidade Federal do Maranhão - UFMA, São Luís, Maranhão.

\author{
*Correspondência: \\ Rua dos Gaviões, quadra \\ 16, no 14, Ponta do Farol, \\ São Luís, MA, \\ Cep 65077-170 \\ Fone: (98) 235-1073. \\ alap@elo.com.br
}

\begin{abstract}
RESUMO
Oвjetivos/Métodos. Avaliou-se a condição periodontal de 30 pacientes, em hemodiálise, através do índice de placa, índice gengival, índice de cálculo, PSR e quantidade de Ig̨A na saliva, visando determinar a condição periodontal de doentes renais crônicos.

Resultados. Os resultados demonstraram que os índices de placa, índice gengival e índice de calculo foram considerados altos nestes pacientes. Com relação à necessidade de tratamento periodontal, observou-se que a maior parte dos pacientes em hemodialise precisava de medidas de higiene bucal, raspagem supra e subgengival e fluoretação tópica (código 2). Em relação aos valores de IğA na saliva, somente três pacientes apresentaram densidade baixa.
\end{abstract}

Conclusäo. Concluiu-se que pacientes renais crônicos em hemodiálise apresentam maior acúmulo de placa bacteriana e elevada formação de cálculo dentário, necessitando de tratamento periodontal como raspagem supra e subgengival.

UNITERMOS: Doenças renais. Hemodiálise. Doenças periodontais.

\section{INTRODUÇÃO}

A insuficiência renal crônica (IRC) representa uma alteração estrutural renal que implica na redução ou limitação da capacidade de filtração glomerular dos rins, causando a uremia, a qual é caracterizada pelo acúmulo no sangue de substâncias que devem ser filtradas e excretadas pelos rins!'

A uremia provoca imunodeficiência devido ao aumento de substâncias tóxicas na corrente sangüínea. Os pacientes com IRC apresentam as respostas imunes celulares e humoral suprimidas e concentrações séricas de lgA, IgM e lgG subnormais em um terço dessa populaçãa. Estudos da IgA salivar em pacientes com doença periodontal e em indivíduos saudáveis têm demonstrado que há diferenças que podem ser usadas na detecção de grupos de alto risco às doenças periodontais².

A IRC pode exibir variadas manifestações bucais como: xerostomia, estomatite urêmica, alterações radiográficas dos ossos maxilares, formação de cálculo dentário decorrente do aumento da concentração de fosfato e cálcio sérico, e outras menos freqüentes ${ }^{1,3}$.

A doença periodontal inflamatória crônica (DPIC) é um processo destrutivo progressivo que afeta os tecidos periodontais, causado por microrganismos que colonizam áreas dentogengivais na forma de placa dental ${ }^{4}$. Várias pesquisas desenvolvidas detectaram que 0 índice de placa em pacientes acometidos por IRC é maior quando comparados com pacientes sistemicamente normais ${ }^{5,6}$.

A existência de possíveis doenças periodontais ou de quaisquer alterações da saúde bucal pode representar focos de infecções aos pacientes renais crônicos em hemodiálise, os quais são extremamente suscetíveis a estas?.

O objetivo desse estudo foi avaliar a condição periodontal e a quantidade de IgA salivar de doentes renais crônicos em hemodiálise, visto que as condições que afetam estes indivíduos (incluindo as doenças periodontais) são fontes de infecçãa, podendo, portanto, ter possíveis implicações na morbidade e mortalidade desses pacientes.

\section{Métodos}

\section{Amostra}

Para constituir amostra desta pesquisa, foram selecionados 30 pacientes atendidos no setor de hemodiálise do Hospital Universitário da Universidade Federal do Maranhão.

Antes do exame, os pacientes selecionados foram submetidos a um questionário-entrevista contendo dados do paciente tais como sexo e idade, condição sistêmica, além de conter o termo de consentimento livre e esclarecido, conscientizando-o da participação na pesquisa. A realização desta pesquisa foi aprovada pelo comitê de ética e pesquisa do Hospital Universitário da Universidade Federal do Maranhão.

\section{Coleta da saliva}

Para coletar a saliva foi dada uma goma de mascar sem açúcar para os pacientes, sendo esta mascada durante um minuto para coleta de $5 \mathrm{ml}$, os quais foram armazenados em pequenos recipientes de vidro, esterilizados e individuais. Esse material foi congelado para posterior análise laboratorial.

\section{Avaliação da condição periodontal}

Os pacientes foram submetidos ao exame periodontal visando determinar o índice de placa, o índice gengival $\left.\right|^{9}$, o índice de cálculo ${ }^{10}$ e o registro periodontal simplificado - PSR".

O exame foi feito sob luz natural, utilizando-se um espelho bucal clínico e uma sonda WHO - 621, que possui uma ponta ativa em forma de esfera de 0,5 mm de diâmetro e uma área codificada em preto de 3,5 a 5,5 mm. Foram realizadas as seguintes análises: 


\section{* Índice de placa}

As quatro superfícies lisas do dente foram avaliadas, atribuindo-se um escore de 0 a 3 a cada uma das superfícies. Os escores foram somados e divididos por quatro, obtendo-se o índice de placa por dente. Ao somar os índices dos dentes e dividir pelo número de dentes examinados, o índice de placa para o paciente foi obtido de acordo com os seguintes critérios: 0 (ausência de placa na região gengival), I (película de placa aderida à gengiva marginal livre e áreas adjacentes do dente), 2 (acúmulo moderado de depósitos dentro da bolsa gengival ou no dente e margem gengival que pode ser vista ao exame clínico) e 3 (abundância de placa dentro do sulco gengival e/ou no dente e margem gengival).

\section{* Índice gengival}

Para o índice gengival, os escores foram atribuídos da seguinte forma: 0 (ausência de inflamação), I (inflamação leve - pequena mudança na cor e textura, ausência de sangramento à sondagem), 2 (inflamação moderada - brilho moderado, vermelhidão, edema e hipertrofia; sangramento à sondagem), 3 (inflamação severa - vermeIhidão acentuada e hipertrofia; sangramento espontâneo; ulceração).

\section{* Índice de cálculo}

Para verificação do índice de cálculo: 0 (ausência de cálculo), I (presença de cálculo supragengival), 2 (presença de cálculo subgengival) e 3 (presença de cálculo abundante).

\section{* PSR}

Na análise do registro periodontal simplificado (PSR), inicialmente, a arcada superior e inferior dos pacientes foram divididas em sextantes, e cada sextante recebeu um código. O sextante anterior se estendia de caninos a caninos, enquanto os sextantes posteriores incluíam pré-molares e molares. Em seguida, foram feitos os exames com a ponta da sonda dentro do sulco gengival percorrendo o colo do dente. A área mais comprometida foi registrada e o sextante edêntulo foi registrado com um " $x$ ", tendo sido utilizados os seguintes códigos:

Código 0 - A porção colorida da sonda está completamente visível. Nenhum cálculo está presente e os tecidos periodontais se encontram saudáveis.

Código I - A porção colorida da sonda está totalmente visível, porém há sangramento após sondagem, mas ainda há ausência de cálculo e de margens gengivais defeituosas.

Código 2 - A porção colorida da sonda está completamente visível, porém há sangramento à sondagem e presença de cálculo supra ou subgengival.

Código 3 - A porção colorida da sonda está parcialmente visível com bolsa periodontal de $4-5 \mathrm{~mm}$.

Código 4 - Faixa colorida da sonda totalmente no interior da bolsa.

\section{* Envolvimento de furca, mobilidade, problemas muco- gengivais}

Para cada código haverá necessidade de tratamento, assim:

Código 0 - Medidas preventivas, ou seja, polimento coronário, fluoretação tópica e ensinamentos de técnicas de higiene oral.

Código I - Instruções de higiene, raspagem da placa supragengival, polimento dos dentes e fluoretação tópica.
Código 2 - Remoção de cálculo, raspagem supra e subgengival, correção de margens defeituosas.

Código 3 - Orientação de higiene oral, raspagem supragengival e subgengival, fluoretação tópica e exame periodontal completo e radiográfico do sextante em questão.

Código 4 - Mapeamento periodontal e exame radiográfico de todos os sextantes, independente do código dos mesmos.

\section{Análise da saliva}

A titulação de anticorpos IgA na saliva foi determinada por ensaio imunoenzimático (teste ELISA) no laboratório de Imunofisiologia da Universidade Federal do Maranhão, segundo o método descrito por Jonhstone e Thorpe ${ }^{12}$.

\section{Resultados}

\section{Resultados clínicos}

Os dados clínicos dos pacientes avaliados, bem como as variáveis analisadas, constam na Tabela I.

Dentre os 30 pacientes constituintes do grupo em hemodiálise, grande parte fazia uso de medicamentos para controle da pressão alta e da anemia, encontrando-se três portadores de diabetes mellitus e nove com uso de algum tipo de prótese caracterizando algum tipo de perda dental (parcial removível ou total).

Quanto aos cuidados com a saúde bucal, observou-se que $80 \%$ da amostra escova os dentes de dois a três vezes ao dia e costuma ir ao cirurgião-dentista somente em casos de dor, sendo que somente 10\% usam fio dental regularmente.

Quando medidos os índices de placa, gengival e de cálculo entre a amostra total do grupo em hemodiálise, foram encontrados os seguintes valores: I,419+0,688,0,589+0,466, I,060 +0,721, respectivamente.

Quando aplicou-se o teste de Tuckey para comparar as médias das variáveis IP, IG e IC entre as arcadas superior e inferior do grupo em hemodiálise, observou-se que a arcada inferior apresentava médias maiores, sendo que esta diferença foi estatisticamente significante.

No que diz respeito ao PSR, quanto à necessidade de tratamento periodontal, o código 2 foi o que predominou nos pacientes em hemodiálise, perfazendo um total de 93,3\%.

\section{Resultados da análise de IgA na saliva}

A análise da lgA na saliva é expressa obtendo-se a média e o desvio padrão dos títulos de lgA nos valores médios de $0,477 \pm 0,195$, sendo que somente três pacientes apresentaram níveis de densidade ótica inferior a 0,200 nm. A Figura I evidencia a distribuição da quantidade de IgA em densidade ótica dos pacientes em hemodiálise.

\section{Discussão}

A literatura estudada indica que pacientes renais crônicos apresentam algumas alterações da saúde bucal, tais como: elevado acúmulo de placa e cálculo dentário, diminuição da secreção salivar, hálito urêmico, palidez da mucosa bucal ${ }^{1,3}$.

No presente estudo, o índice de placa nos pacientes em hemodiálise foi considerado alto, com média de I,4|9. Tais resulta- 


\begin{tabular}{|c|c|c|c|c|c|c|c|c|c|c|c|c|c|c|}
\hline \multicolumn{15}{|c|}{ Tabela I - Pacientes em hemodiálise } \\
\hline \multirow[b]{2}{*}{ Nome } & \multirow[b]{2}{*}{$\mathbf{N}^{0}$} & \multirow[b]{2}{*}{ Idade } & \multirow[b]{2}{*}{ Sexo } & \multirow[b]{2}{*}{$\mathbb{P}$} & \multirow[b]{2}{*}{ IG } & \multirow[b]{2}{*}{ IC } & \multicolumn{6}{|c|}{ PSR } & \multicolumn{2}{|c|}{$\lg A$} \\
\hline & & & & & & & $\underline{0}$ & 1 & $\underline{2}$ & $\underline{3}$ & $\underline{4}$ & $\underline{x}$ & $\mathrm{~nm}$ & $\mathrm{mg} / \mathrm{ml}$ \\
\hline A.M. & $\overline{1}$ & $\overline{46}$ & $\bar{M}$ & $\overline{2,14}$ & $\overline{1,40}$ & $\overline{2,17}$ & $\overline{0}$ & $\overline{0}$ & $\overline{2}$ & $\overline{0}$ & $\overline{0}$ & $\overline{4}$ & 0,127 & 3,96 \\
\hline J.E. & 2 & 25 & M & 0,80 & 0,28 & 0,76 & । & 0 & 5 & 0 & 0 & 0 & 0,534 & 17,05 \\
\hline P.C. & 3 & 27 & M & 0,51 & 0,10 & 0,23 & । & 0 & 5 & 0 & 0 & 0 & 0,324 & 9,80 \\
\hline L.S. & 4 & 42 & $F$ & 1,66 & 1,04 & $|, 5|$ & I & 0 & 5 & 0 & 0 & 0 & 0,370 & 11,09 \\
\hline A.L. & 5 & 42 & $M$ & 1,75 & 0,22 & 1,25 & 0 & 0 & 2 & 0 & 0 & 4 & 0,331 & 9,19 \\
\hline I.S. & 6 & 34 & $M$ & 2,04 & 0,66 & 0,95 & 1 & 0 & 3 & 0 & 0 & 2 & 0,792 & 20,32 \\
\hline R.N. & 7 & 61 & $M$ & 3,00 & 1,00 & 3,00 & 0 & 0 & 0 & 0 & I & 5 & 0,585 & 18,26 \\
\hline V.F. & 8 & 62 & $M$ & 2,80 & 1,60 & 2,40 & 0 & 0 & I & 0 & 0 & 5 & 0,483 & 15,23 \\
\hline M.J. & 9 & 44 & $M$ & 1,02 & 0,87 & 1,03 & I & 0 & 4 & 0 & 0 & I & 0,401 & 12,58 \\
\hline J.R. & 10 & 35 & $M$ & 1,25 & 0,66 & 0,66 & 0 & 0 & I & 0 & 0 & 5 & 0,248 & 7,23 \\
\hline J.M. & 11 & 20 & $\mathrm{~F}$ & $|, 7|$ & 1,60 & 2,20 & 0 & 0 & 5 & | & 0 & 0 & 0,456 & 13,44 \\
\hline I.G. & 12 & 30 & $\mathrm{~F}$ & 1,16 & 0,15 & 0,71 & 0 & 0 & 6 & 0 & 0 & 0 & 0,132 & 2,95 \\
\hline D.D. & 13 & 32 & $\mathrm{~F}$ & $|, 3|$ & 0,22 & 0,75 & I & 0 & 5 & 0 & 0 & 0 & 0,403 & 12,13 \\
\hline G.M. & 14 & 18 & $F$ & 1,66 & 0,35 & 0,50 & 0 & 0 & 3 & 0 & 0 & 3 & 0,717 & 22,90 \\
\hline L.C. & 15 & 56 & $M$ & 0,88 & 0,09 & 0,65 & I & 0 & 5 & 0 & 0 & 0 & 0,485 & 15,18 \\
\hline M.J. & 16 & 59 & $M$ & 1,20 & 0,30 & 1,60 & 0 & 0 & I & 0 & 0 & 5 & 0,435 & $\mid 4,65$ \\
\hline M.E. & 17 & 42 & $F$ & 1,95 & 0,72 & 1,60 & 0 & 0 & 3 & 0 & 0 & 3 & 0,698 & 21,63 \\
\hline M.C. & 18 & 40 & $\mathrm{~F}$ & 0,89 & 0,13 & 0,61 & 1 & 0 & 5 & 0 & 0 & 0 & 0,614 & 19,43 \\
\hline J.A. & 19 & 51 & $M$ & 1,50 & 0,13 & 0,40 & 0 & 0 & 4 & 0 & 0 & 2 & 0,299 & 10,20 \\
\hline P.R. & 20 & 32 & $M$ & 1,54 & 0,35 & 1,12 & 0 & 0 & 6 & 0 & 0 & 0 & 0,686 & 21,90 \\
\hline F.J. & 21 & 25 & $F$ & 1,83 & 1,06 & 0,56 & 0 & I & 5 & 0 & 0 & 0 & 0,451 & 14,66 \\
\hline A.F.J. & 22 & 26 & $\mathrm{~F}$ & 2,50 & 0,77 & 1,70 & 0 & 0 & 6 & 0 & 0 & 0 & 0,599 & 18,17 \\
\hline J. S. & 23 & 43 & $F$ & 1,75 & 0,32 & 1,82 & 0 & 0 & I & 0 & 0 & 5 & 0,531 & 16,44 \\
\hline C.M. & 24 & 19 & $F$ & 1,44 & 0,62 & 0,32 & 0 & 0 & 6 & 0 & 0 & 0 & 0,399 & 16,09 \\
\hline Z.P. & 25 & 77 & $F$ & 0,56 & 1,10 & 0,81 & I & 0 & 3 & 0 & 0 & 2 & 0,637 & 20,97 \\
\hline R.C. & 26 & 14 & $M$ & 1,66 & 0,15 & 0,19 & I & 0 & 5 & 0 & 0 & 0 & 0,480 & 15,10 \\
\hline C.M. & 27 & 56 & $F$ & 0,70 & 0,15 & 0,72 & 1 & 0 & I & 0 & 0 & 4 & 0,643 & 21,76 \\
\hline M.R. & 28 & 18 & $\mathrm{~F}$ & 0,23 & 0,21 & 0,11 & 3 & 0 & 3 & 0 & 0 & 0 & 0,129 & 3,41 \\
\hline A.S. & 29 & 32 & $M$ & 0,63 & 0,71 & 0,89 & 0 & 0 & 6 & 0 & 0 & 0 & 0,519 & 16,44 \\
\hline R.M. & 30 & 19 & $\mathrm{~F}$ & 0,47 & 0,11 & 0,60 & I & 0 & 5 & 0 & 0 & 0 & 0,268 & 7,87 \\
\hline
\end{tabular}

Fonte: Hospital Universitário Dutra-2002

dos concordam com os estudos de Rahman, Çaglayan e Rahman'3, Gavaldá et al. ${ }^{14}$, Klassen e Krasko ${ }^{15}$, discordando, porém, das pesquisas de Kitsou, Konstatinidis e Siamopoulus ${ }^{16}$ e Marakoglu et al. ${ }^{17}$ Segundo Naugler et al. ${ }^{6}$, a explicação para o maior acúmulo de placa em pacientes renais crônicos seria o fato de que eles se preocupam tanto com a condição sistêmica que negligenciam a saúde bucal. Este resultado evidencia a deficiência na higiene bucal desses pacientes, devendo-se, portanto, priorizar um programa de promoção de saúde bucal a estes pacientes tanto em ambiente hospitalar como em campanhas de saúde pública.

Quanto ao índice gengival, os pacientes objeto deste estudo apresentaram índices médios de 0,589, resultados estes semelhantes aos trabalhos de Kitsou, Konstatinidis, Naugle et al. ${ }^{16}$ Contudo, os resultados não coincidem com os achados de Yamaliki et al. ${ }^{18}$, Rahman, Çaglayan e Rahman ${ }^{13}$ e Marakoglu et al. ${ }^{17}$, que obtiveram índice gengival menor nos pacientes em hemodiálise quando comparados a grupos controles, embora essa diferença não tenha sido significativa. Apesar do maior acúmulo de placa bacteriana que esses pacientes apresentaram, não houve inflamação gengival compatível com tal grau de agressão. Segundo Jaffe et al. ${ }^{19}$, a justificativa para o menor índice gengival nos pacientes em hemodiálise seria a anemia, que acomete grande parte desses pacientes e mascara a inflamação dos tecidos gengivais, havendo uma resposta inflamatória menor ao hospedeiro.

Segundo Epstein, Mandel e Scopp ${ }^{20}$, a explicação para uma maior formação de cálculo em doentes renais crônicos seria a concentração salivar de uréia aumentada e uma média menor de fluxo salivar, sendo outra justificativa para este fato o alto suplemento de cálcio e fósforo freqüentemente usado por estes pacientes ${ }^{19}$. Na presente pesquisa, o índice de cálculo nos pacientes em hemodiálise foi considerado alto com valor médio de 1,060, o que está também de acordo com os achados de Fujimaki, Rosa e Torres ${ }^{21}$, Gavaldá et al. ${ }^{14}$.

Klassen e Krasko ${ }^{15}$ avaliaram o grau de saúde bucal em pacientes submetidos à diálise utilizando o PSR, verificando negligência bucal por parte desses indivíduos, fato este também verificado na presente pesquisa, na qual a maioria dos pacientes em hemodiálise apresentaram código 2.

A pobre saúde bucal em pacientes renais crônicos em diálise foi observada também nas pesquisas de Meyerowitz ${ }^{22}$ e Fujimaki, Rosa, 


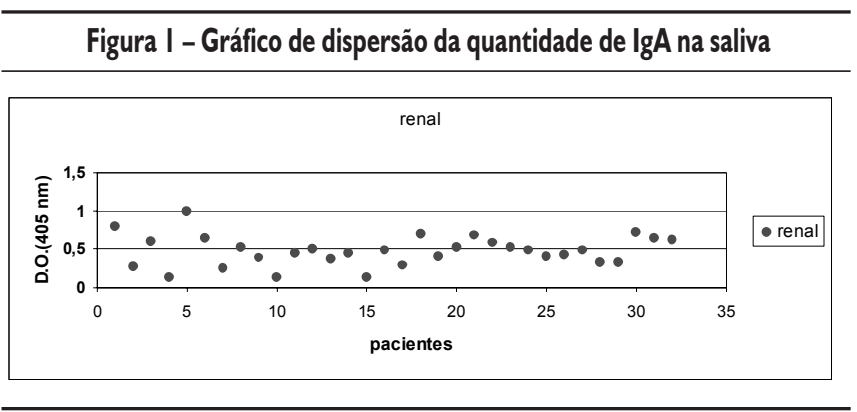

Torres ${ }^{21}$, os quais comentaram que pacientes renais crônicos em hemodiálise geralmente não apresentam saúde bucal aceitável, justificando que tais pacientes não buscam serviços odontológicos regularmente, somente os utilizando em casos de urgência, necessitando de atenção odontológica especial e conscientização de que as infecções bucais podem trazer sérias complicações ao quadro sistêmico em pacientes renais crônicos por representarem focos de infecção.

Apesar de um maior acúmulo de placa bacteriana, não foi possível detectar uma relação com os valores de lg̈ na saliva. Vale ressaltar que três pacientes renais apresentaram valores considerados baixos nessa dosagem $(<0,200 \mathrm{~nm})$. O estudo de Dobbestein ${ }^{23}$ é o único reportado à quantidade de IgA em pacientes em diálise, indicando que $I / 3$ dessa população apresenta concentrações séricas de IgA abaixo do normal.

Pacientes diabéticos apresentam índices de placa e gengival significantemente elevados quando comparados com indivíduos sistemicamente saudáveis ${ }^{24}$. Sendo assim, pôde-se observar que dos três pacientes diabéticos que se submetiam à hemodiálise, um apresentou índices de placa, gengival e de cálculo bastante elevados quando comparados com os outros pacientes, assim como dosagem salivar de $\lg A<0,200$.

\section{Conclusão}

Com a realização desta avaliação, pôde-se concluir que os pacientes em hemodiálise apresentaram grande acúmulo de placa bacteriana e elevada formação de cálculo dentário, sendo que as arcadas inferiores apresentaram-se mais afetadas que as superiores. O grau de inflamaçãa gengival não traduz a grande presença de placa e cálculo, portanto, demonstrando que tais pacientes não têm a resposta inflamatória prejudicada pela insuficiência renal crônica.

Pacientes em hemodiálise necessitam de atenção odontológica e orientações de higiene bucal, devendo ser conscientizados da importância da saúde bucal na manutenção de sua saúde sistêmica.

Conflito de interesse: não há.

\section{SUMMARY}

\section{Assessment of Periodontal condition of kidney patients IN HEMODIALYSIS}

OBJECTIVESANDMETHODS. Thirty patients undergoing hemodialysis were evaluated for their periodontal condition through plaque, calculus and gingival indexes; PSR and IgA present in the saliva were also appraised in order to determine the periodontal condition of patients presenting chronic kidney disease.

RESULTS. Results obtained demonstrated that in the studied group the plaque, calculus and gingival indexes were high. With regard to these patients' requirement to undergo periodontal treatment, most patients submitted to hemodialysis needed better oral hygiene, in addition to supra and sub gingival scraping and topic application of fluor (code 2). As to the IgA amount present in the saliva, only three patients showed a low density.

CONCLUSIONS. Patients presenting chronic kidney disease disclosed a tendency for greater bacterial plaque concentration, high formation of dental calculus suggesting the need for periodontal treatment comprising supra and sub gingival scraping. [Rev Assoc Med Bras 2005; 5 I(5): 285-9]

KeY words: Kidney diseases. Hemodialysis. Periodontal diseases.

\section{RefERÊNCIAS}

I. Mesquita RA, Carvalho AA, Pereira AS, Araújo NS, Magalhães MHCG. Considerações odontológicas no atendimento ambulatorial de pacientes com insuficiência renal crônica. Rev Pós-Grad 2000;7: 369-75.

2. Bokor-Bratic M. Clinical significance of analysis of immunoglobulin A levels in saliva. Med Pregl 2000;53: I64-8.

3. De Rossi SS, Glick M. Dental considerations for the patient with renal disease receiving hemodialysis. J Am Dental Assoc 1996; I 27:2 I I-9.

4. American Academy of Periodontology. International workshop for a classification of periodontal diseases and conditions. Ann Periodontol 1999;4:4-53.

5. Been $V$, Engel D. The effects of immunosupressive drugs on periodontal inflamation in human renal allograft patients. J Periodontol 1982;53:245-8.

6. Naugle K, Darby ML, Bauman DB, Lineberger LT, Powers R. The oral health status of individuals on renal dialysis. Ann Periodontol 1998;3:197-205.

7. Sowell SB. Dental care for patients with renal failure and renal transplants. J Am Dental Assoc 1982; 104: 17 I-7.

8. Silness J, Löe H. Periodontal disease in pregnancy. II. Correlation between oral hygiene and periodontal condition. Acta Odontol Scand 1964;22:121-35.

9. Löe H, Silness J. Periodontal disease in pregnancy. I. Prevalence and severity. Acta Odontol Scand 1963;21:533-51.

10. Björby A, Löe H. The relative significance of different local factors in the initiation and development of periodontal inflamation. J Periodont Res 1967;2:Abstract; 76-77

1।. The American Academy of Periodontology and American Dental Association. Periodontal Screening and Recording; 1993.

12. Johnstone A, Thorpe R. Immunoassays. In: Immunochemistry in practice 2th ed. London: Blackwell; 1987.

13. Rahman MM, Çaglayan F, Rahman B. Periodontal health paramenters in patients with renal failure and renal transplants receiving immunosuppressive therapy. J Nihon University School Dental 1992; 34:265-72.

14. Gavaldá C, Bagan J, Scully C, Silvetre F, Milian M, Jimenez Y. Renal hemodialysis patients: oral, salivary, dental and periodontal findings in I05 adult cases. Oral Med 1999;5:299-303.

15. Klassen JT, Krasko BM. The dental health status of dialysis patients. J Can Dental Assoc 2002;68:34-8.

16. Kitsou VK, Konstantinidis A, Siamopoulus KC. Chronic renal failure and periodontal disease. Renal Failure 2000;22:307- I 8.

17. Marakoglu I et al. Periodontal Status of chronic renal failure patients receiving hemodialysis. Yonsei Med J 2003;44:648-52. 
18. Yamalik N. et al. The histological investigation of gingiva from patients with chronic renal failure, renal transplants, and periodontitis: a light and electron microscopic study. J Periodontol | 99|;62:737-44.

19. Jaffe EC, Roberts GJ, Chantler C, Carter JE. Dental findings in chronic renal failure. Brit Dent I 1986; | 60: I 8-20

20. Epstein SR, Mandel I, Scopp IW. Salivary composition and calculus formation in patients undergoing hemodialysis. J Periodontol 1980; 51:336-8.

21. Fujimaki M, Rosa OPS, Torres SA. Microrganismos cariogênicos em pacientes com insuficiência renal crônica em hemodiálise. Rev Fac Odontol Univ São Paulo 1998; | 2: |49-58.

22. Meyerowitz C. Cáries nos pacientes de diálise renal. In: Bowen WH,
Tabak L. A Cardiologia para a década de 90. São Paulo: Santos, 1995. p. 249-60.

23. Dobbestein H. Immune system in uremia. Nephron 1976; 17:409- I 4.

24. Novaes Jr AB, Pereira AL, Moraes N, Novaes AB. Manifestation of insulin-dependent diabetes mellitus in the periodontium of young brazilian patients. J Periodontol 1991;62: | | 6-22.

Artigo recebido: 16/06/04

Aceito para publicação: 01/09/04 